\title{
ALGUNAS PRECISIONES SOBRE LA DECLARACION DE IMPACTO AMBIENTAL EN ARAGON
}

\author{
POR \\ Javier Olivan del Cacho.
}

SUMARIO: 1. INTRODUCCION: EL PRONUNCIAMIENTO CONSTITUCIONAL SOBRE EL MEDIO AMBIENTE. 2. LA DISTRIBUCION COMPETENCIAL EN LA MATERIA. 3. LA REGULACION ESTATAL DE IMPACTO AMBIENTAL. A) La normativa europea. B) El Decreto Legislativo 1302/1986. 4. LA NORMATIVA ARAGONESA Y EL INSTITUTO ARAGONÉS DEL MEDIO AMBIENTE. A) La primera regulación. B) El Instituto Aragonés del Medio Ambiente y el D. 148/1990, de 9 de noviembre.

1. INTRODUCCION: EL PRONUNCIAMIENTO CONSTITUCIONAL SOBRE EL MEDIO AMBIENTE.

La Evaluación de Impacto Ambiental (EIA) se inserta de lleno en un problema de difícil resolución, cual es la compatibilidad entre desarrollo económico -plasmado en proyectos privados empresariales o en infraestructuras públicas- y la protección del medio ambiente. Efectivamente, la EIA parte del sistema americano de valoración costes-beneficio de un determinado proyecto (cost-benefit analisys) (1).

Dicho esto, no cabe duda de que la posición de la Constitución española (CE) en lo relativo a la relación medio ambiente-desarrollo económico será decisiva en la realización de dicho análisis.

El art. 45 de la CE recoge el derecho-deber a disfrutar a un medio ambiente adecuado y plantea una serie de obligaciones para los Poderes Públicos, no sólo en lo relativo a la protección, sino también en lo concerniente a su promoción y mejora (2). Sin embargo, el Texto Fundamental también encomienda a las instancias públicas un compromiso activo en el desarrollo de todos los sectores económicos o garantiza la libertad de empresa en el art. 38.

(1) Vid. E. CAPIZANO, Per un Diritto Agrario Ambientale. "Rivista di diritto agrario", I, 1987, pp. 443.

(2) Vid., para la exégesis del precepto, lo expuesto por I. PONT CASTEJON, Medio ambiente y Constitución española de 1978, en "La empresa en la Constitución española", de. Aranzadi, Pamplona, 1989, pp. 315 y ss. 
Como era de esperar, ha sido lo que bien puede denominarse jurisprudencia medioambiental del Tribunal Constitucional la que ha efectuado una toma de postura en la cuestión (3). Dos han sido los pronunciamientos del TC que interesan a estos efectos. En el primero de ellos, que versó sobre la Ley catalana por la que se establecian normas adicionales de protección de los espacios de especial interés natural afectados por actividades extractivas, se declaró la existencia de ambos valores constitucionales -medio ambiente y promoción económica-, correspondiendo al legislador hallar la forma de compaginar ambos bienes jurídicos (4). Opción realizada por los titulares de la potestad legislativa que, evidentemente, podrá ser fiscalizada por el TC (5).

La segunda Sentencia anunciada -la 170/1989, de 19 de octubrecorresponde al recurso de inconstitucionalidad planteado contra la Ley madrileña del Parque Regional de la Cuenca Alta del Manzanares. En esta ocasión, el TC expuso que la valoración realizada por el legislador autonómico fue adecuada a la Constitución, debido a que las restricciones efectuadas en la libertad de empresa -relacionada con actividades extractivas- tuvieron un "carácter territorialmente limitado" y "una escasa repercusión en el interés general económico".

Por su parte, la jurisprudencia del Tribunal Supremo también ha tenido que enfrentarse a esta contradicción. Empieza a ser conocida una línea jurisprudencial -de la que ha sido ponente el Pfr. GONZALEZ NAVARRO- en la que se está dotando de eficacia jurídica el

(3) La jurisprudencia del TC en la materia ha sido la siguiente: STC 64/1982, de 4 de noviembre, en relación a la Ley 12/1981, de 24 de diciembre, del Parlamento de Cataluña, por la que se establecian normas adicionales de protección de los espacios de especial interés natural afectados por actividades extractivas; la STC 82/1982, de 21 de diciembre, en relación a la Ley catalana de declaración como paraje natural de interés nacional del Macizo de Pedraforca: STC 227/1988, de 29 de noviembre, sobre la Ley 29/1985, de Aguas; y, finalmente, la STC 170/1989, de 19 de octubre, sobre la Ley madrileña del Parque Regional de la Cuenca Alta del Manzanares.

(4) Lo que parece claro es el veto a fórmulas de desarrollo economicista y sin ningún tipo de preocupación por el crecimiento ordenado. Vid., en este orden de cosas, el estudio de T.R. FERNANDEZ, Derecho, Medio Ambiente y Desarrollo, "REDA", núm. 24 (1980), pp. 8 y ss., donde manifiesta, recién aprobada la Constitución, que ésta no renuncia, pues, al crecimiento y al desarrollo pero quiere cerrar el camino a un tipo de desarrollo -el que padecimos en la década de los setenta- que todo lo subordina al crecimiento puro y simple de las grandes magnitudes económicas..."

Sobre el concepto del ecodesarrollo, vid. R. MARTIN MATEO, Economía, desarrollo, ecología y ordenación del territorio. "RDU", núm. 110, (1988), pp. 21.

(5) En este sentido, el Tribunal consideró dos preceptos legales inconstitucionales, precisamente, por considerar violados los principios económicos constitucionales en aras de una protección rigurosa del medio ambiente. 
principio constitucional relativo a la protección del medio ambiente, generándose, ante todo, un clima interpretativo de la legislación favorable a la defensa medioambiental (6). Basta aquí citar algún exponente jurisprudencial para comprobar la rotundidad de esta jurisprudencia. Así, el Auto del TS de 11 de mayo de 1989 -por la que se suspendió una autorización de apertura a una Discoteca- manifestó que "una vez más...se encuentran enfrentados los intereses de dos particulares, cada uno de los cuales puede encontrar apoyatura en preceptos constitucionales -derecho al descanso y a un medio ambiente adecuado...y derecho al ejercicio de una actividad empresarial...". El Alto Tribunal siguió diciendo, para justificar esta suspensión, que "el derecho a un medio ambiente adecuado cobra en nuestros días un valor preeminente como lo prueba la reciente Ley de 27 de marzo de 1989 de conservación de espacios naturales y de la flora o fauna silvestre, donde se establece la prevalencia de la planificación medioambiental sobre cualesquiera otra territorial o física" (7).

Se observa, pues, una creciente necesidad de ponderación de las implicaciones medioambientales de las diferentes iniciativas económicas, bien se trate de instalaciones fabriles o empresariales o de infraestructuras vinculadas al progreso económico (8). En este marco, la E.I.A., en cuanto supone un examen de los efectos de determinadas obras o proyectos sobre el medio ambiente, se incardina de modo directo en este contexto.

(6) T. QUINTANA (Justicia administrativa, medio ambiente y servicios municipales, "REDA", núm. 65, 1990, pp. 113) considera de modo muy favorable la Sentencia de 25 de abril de 1989 que reconoció la legitimación a un vecino para impugnar la negativa de un Ayuntamiento ante su petición de subsanación de las instalaciones de tratamiento y evacuación de aguas residuales del municipio. Interpretación en favor de la protección del medio ambiente derivado, pues, de que ese "artículo 45, como los demás del expresado capítulo, tienen valor normativo y vinculan a los poderes públicos, cada uno en su respectiva esfera. Por todo ello, es claro que el recurrente tiene legitimación sobrada para acceder a los Tribunales de Justicia a plantear la cuestión aqui debatida".

(7) A esta decisión judicial se refiere el profesor SOSA WAGNER (La lucha contra el ruido. "REVL/REALA", núm. 249, (1991), pp. 21), calificando de estupendo el razonamiento del Tribunal.

En lo relativo a contaminación acústica, es de inexcusable referencia lo expuesto por el Pfr. Lorenzo MARTIN RETORTILLO, La defensa frente al ruido ante el Tribunal Constitucional. "RAP", núm. 115, (1988), pp. 221, quien vincula el artículo 18 de la Constitución y la proscripción de "intromisiones arbitrarias" con la contaminación por ruidos no legítimos.

(8) Véase, en este orden de cosas, el estudio del Pfr. R. MARTIN MATEO, La calidad de vida como valor jurídico." RAP" núm. 117, (1988), pp. 51 y ss. 


\section{LA DISTRIBUCION COMPETENCIAL EN LA MATERIA.}

Como es bien sabido, la Comunidad Autónoma (CA) de Aragón accedió al régimen de autonomía por la vía del art. 143 de la Constitución española, lo cual redujo su nivel competencial dentro de los límites que posibilitaba el art. 148 del Texto Fundamental (9). En este sentido, la C.A. de Aragón vería frustrado cualquier intento de desarrollo normativo del art. 149.1.23 que reconoce como competencia estatal la legislación básica de protección del medio ambiente sin perjuicio del establecimiento de normas adicionales de protección por las Comunidades Autónomas.

En esta lógica, los Poderes Públicos aragoneses se limitarían a la ejecución de la legislación del medio ambiente estatal. Quedaban, sin embargo, dentro de las posibilidades autonómicas el establecimiento de normas organizativas así como la aprobación de especialidades procedimentales, enmarcadas, siempre, dentro de esta potestad ejecutiva (10). No obstante, fueron objeto de asunción competencial materias relativas a distintos recursos naturales, fundamentalmente, montes y espacios naturales, pero se discutía la legitimidad constitucional de dicha atribución. Considero, en este sentido, el ajuste constitucional de la previsión estatutaria, siguiendo la argumentación ofrecida por el profesor LOPEZ RAMON (11).

(9) Efectivamente, el art. 148.9 de la CE permite la asunción de competencias "en la gestión en materia de protección del medio ambiente".

(10) Medidas organizativas que podian conllevar, obviamente, el ejercicio de potestad legislativa. Véase, por ejemplo, la Ley madrileña $3 / 1988$, de 13 de octubre, para la gestión del medio ambiente que incluía una medida organizativa concretada en la creación de la Agencia de Medio Ambiente, configurada como Organismo autónomo.

(11) Vid. Comentarios al Estatuto de Autonomía de la Comunidad Autónoma de Aragón, dirigidos por el profesor BERMEJO VERA, Ministerio de Administración Territorial-Instituto de Estudios de Administración Local, Madrid, 1985, pp. 389. Fernando LOPEZ RAMON expresa lo siguiente: "En concreto, al reconocimiento de la competencia autonómica sobre tales espacios podría llegarse, al menos, por cuatro caminos:

a) Incluir la protección de espacios naturales en la materia forestal, con fundamento en el artículo 148.8 Const. Vía interpretativa que parece seguir el Estatuto aragonés y cuenta a su favor con datos históricos (la tradicional vinculación de los parques nacionales $y$ demás espacios naturales protegidos a la Administración Forestal, de forma que hasta la vigente Ley de Espacios Naturales Protegidos, éstos se regulaban en la propia Ley de Montes) y jurídico-positivos (técnicamente los espacios naturales protegidos pueden ser calificados, en la mayoria de los supuestos, como montes).

b) Considerar que la materia es un aspecto particular de las atribuciones sobre ordenación del territorio y urbanismo (ex art. 148.1.3 Const.) como se ha entendido parcialmente en Italia.

c) Estimar comprendida la protección de espacios naturales en las competencias de gestión sobre el medio ambiente (ex. art. 148.1.9 Const.)... 
Dos hechos han complicado este panorama, que algunos consideraban desalentador, para las CC.AA. de segundo grado:

a) Por un lado, la aprobación de la Ley de Espacios Naturales y de Protección de la Flora y Fauna silvestre que se remite al desarrollo legislativo de las diferentes CC.AA. (12)

b) La Sentencia del Tribunal Constitucional (TC) que enjuició la alegada inconstitucionalidad de la Ley de la CA de Madrid $1 / 1985$, de 23 de enero, del Parque Regional de la Cuenca Alta del Manzanares que, finalmente, consideró conforme a la Constitución. La importancia de la decisión del TC abarca varios aspectos de trascendental importancia entre ellos, la -interesante cuestión ya vista de la relación entre desarrollo económico y protección del medio ambiente-, pero, para el asunto tratado, interesa centrarse en el análisis del debate competencial.

La discusión se centraba en el establecimiento de una figura de protección -el Parque Regional- de un espacio de la Comunidad de Madrid. Los recurrentes alegaban, entre otras cosas, la ausencia de competencia de la Asamblea Legislativa de la Comunidad citada para dictar una Ley ambiental. El letrado de la CA, Profesor Tomás Ramón FERNANDEZ, intentó reconducir la materia regulada al concepto de espacio natural, vinculado, a su vez, a títulos competenciales autónomicos como la ordenación del territorio (13).

d) Por último, utilizando todos estos criterios simultáneamente, considerar que las competencias sobre los espacios naturales protegidos deben corresponder a la Comunidad Autónoma por disponer de las atribuciones instrumentales precisas para asegurar el régimen de actividades en que se traduce la protección de un espacio natural: competencias sobre urbanismo, medio ambiente, montes, turismo, fauna, etc..."

(12) Vid, especialmente, el art. 21 con el que se pueden relacionar la Ley 2/1990, de las Cortes de Aragón, de 21 de marzo, de Glaciares Pirenáicos, en coherencia con el art. 20 del Estatuto de Autonomía; la Ley 14/1990, de 27 de diciembre, por la que se declara el Parque de la Sierra y Cañones de Guara y la Ley 5/1991, de 8 de abril, de declaración de la Reserva Natural de los Galachos de la Alfranca de Pastriz, La Cartuja y EI Burgo de Ebro.

(13) El TC recoge las alegaciones de la Comunidad en su Fundamento Jurídico segundo: "Por su parte, la representación del Consejo de Gobierno de la Comunidad de Madrid mantiene que la regulación sobre espacios naturales protegidos es un concepto referencial que se utiliza para designar unitariamente un complejo muy diverso de técnicas de intervención sobre un espacio físico, del que forman parte distintas materias en el sentido propio de la expresión, de forma que podria aducirse una serie de títulos competenciales (ordenación del territorio, agricultura y ganaderia, pesca y caza, promoción y ordenación y turismol que cubririan sobradamente la totalidad de las normas que integran la ley impugnada". 
No aceptó el TC el planteamiento del profesor madrileño, expresando que la cuestión discutida se centraba en el medio ambiente. Esta consideración del TC hace, si cabe, más interesante el contenido doctrinal de la Sentencia, pues reconoce la existencia de potestades legislativas a la CA de Madrid y, por ende, a las CC.AA. de segundo grado, "siempre dentro del respeto de la legislación básica", si así lo establecen sus Estatutos (14).

Dos consideraciones interesa formular respecto a la acomodación de esta decisión del TC a los planteamientos constitucionales que son, como se ha visto, bastante restrictivos en tanto no se produzca la reforma estatutaria o se haga uso de algún otro mecanismo de ampliación competencial.

La primera reflexión haría referencia a la vinculación de las competencias de desarrollo normativo de las CC. AA. de segundo grado con las normas adicionales de protección -así reconocida en esta jurisprudencia- que el art. 149. 1. 23 de la CE permite establecer a las CC. AA, dentro de lo fijado en las normas estatutarias. Lo cierto es que, a diferencia de lo previsto en el Estatuto de Autonomía de la Comunidad de Madrid, no existe en el de Aragón referencia alguna a las normas adicionales de protección, existiendo tan sólo una atribución en la ejecución de la legislación del Estado y la ya citada referencia a la competencia en espacios naturales del art. 35 de la norma estatutaria (15).

La segunda no haría, sino retomar las argumentaciones del Profesor T.R. FERNANDEZ, en el sentido de reparar en las vinculaciones de la competencia en protección medioambiental con otros títulos competenciales autonómicos como la ordenación del territorio, montes o la submateria espacios naturales. En este punto, el Estatuto de Autonomía aragonés reconoce competencia a la CA de Aragón dentro del respeto de la legislación básica.

Esta vinculación de materias directamente relacionadas pueden servir de soporte habilitador para la existencia de un cierto desarrollo normativo que pudiese afectar a lo medioambiental. Seria

(14) EI TC finaliza su Fundamento Juridico segundo reconociendo que "la ley autonómica, respetando esa legislación básica, puede también completar o reforzar los niveles de protección previstos en esa legislación básica, siempre que estas medidas legales autonómicas sean compatibles, no contradigan, ignoren, reduzcan o limiten la protección establecida en la legislación básica del Estado. Lo que precisamente se ha de examinar en relación con la ley impugnada es, pues, si la misma resulta compatible y no contradice la legislación básica del Estado".

(15) El art. 35.1.10 del EEA atribuye la competencia a la Comunidad Autónoma de Aragón en "Montes, aprovechamientos y servicios forestales, vías pecuarias, pastos y espacios naturales protegidos, en el marco de la legislación básica del Estado". 
perfectamente posible, como luego se verá, en el tema concreto objeto de análisis -la Evaluación de Impacto Ambiental- añadir supuestos -vinculados a esas materias asumidas- a la lista fijada en los correspondientes anexos de la legislación estatal.

Examinada, pues, la situación competencial que parece permitir a la C.A. de Aragón -apoyándose en esta segunda argumentaciónun cierto margen de maniobra en lo que se refiere al desarrollo normativo, es pertinente abordar la regulación estatal, no sin antes realizar una breve referencia a los precedentes normativos comunitarios (16).

\section{LA REGULACION ESTATAL DE IMPACTO AMBIENTAL.}

\section{A) La normativa europea.}

La Directiva 85/377/CEE, de 27 de junio, es la premisa de toda la normativa estatal $y$, obviamente, de su desarrollo autonómico (17). En este instrumento normativo comunitario se recogen los principios de la regulación, el ámbito de aplicación, el contenido de la Evaluación de Impacto Ambiental (EIA) y de los proyectos a presentar por el promotor y una serie de exigencias procedimentales concretadas en la necesidad de información pública y en el respeto al secreto empresarial.

En efecto, la Directiva parte de la obligación de sometimiento a EIA de los proyectos que puedan tener repercusiones en el medio ambiente. Evaluación que comprenderá los efectos directos e indirectos en el hombre, la fauna y la flora, es decir, en los seres vivos; en la base de presencia de los seres vivos, como el suelo, el aire, el agua, el clima y el paisaje; la interacción entre los factores mencionados y en los bienes materiales y patrimonio cultural.

Respecto a las relaciones entre esta Directiva y la normativa nacional, el instrumento comunitario fijaba un plazo de tres años, a partir de

(16) La cuestión dista todavía de ser pacifica. Un hecho simbólico de esta pugna, que no hace sino reflejar la necesidad imperiosa de ampliar el techo competencial de CC.AA. como la de Aragón, es la reciente elevación de una cuestión de inconstitucionalidad en relación a la Ley $1 / 1984$, de 14 de marzo, de ordenación y protección de áreas naturales de protección especial que vuelve a plantear de nuevo el alcance de la atribución sobre normas adicionales de protección en una CA de autonomía ordinaria.

(17) La incidencia del Derecho comunitario del medio ambiente es notoria y muy trascendente. Vid., para esta cuestión, el interesante libro de E. VALERIO, La legislación europea del medio ambiente: su aplicación en España, de. Colex, Madrid, 1991. 
su notificación, para que los Estados miembros dictasen las medidas necesarias para su cumplimiento. Conviene recordar, en este sentido, los principios de la normativa comunitaria sobre la primacía y el efecto directo. Este último carácter, concretado en el nacimiento de derechos para los particulares, no es una consecuencia inmediata de la Directiva pero si, en expresión de A. MANGAS MARTIN, aparece como resultado de la inejecución de tales medidas por el Estado miembro (18).

La Directiva 85/337/CEE contiene dos importantes concesiones, sin embargo, a las normas de los Estados. Por un lado, permite establecer normas más severas -en coherencia, por cierto, con el Acta Unica (19)- y, por otro, consagra la exclusión de esta obligatoriedad de sometimiento a las EIA a los proyectos relacionados con la Defensa Nacional y aquellos otros aprobados por Ley. Igualmente, en casos excepcionales, se permite exceptuar de la aplicación de esta técnica de protección a determinados proyectos o parte de ellos. En este caso, el Estado miembro tiene la obligación de examinar la conveniencia de otra forma de evaluación y de poner a disposición del público interesado las informaciones y razones relativas a dicha exención. Finalmente, existe el deber de informar a la Comisión -con carácter previo a la concesión de una autorización- sobre los motivos que conllevan dicha exceptuación y la obligación de proporcionarle las informaciones que, eventualmente, se pongan a disposición de sus propios nacionales.

Finalmente, la Directiva incluye dos anexos. En el primero de ellos, aparecen los proyectos que necesariamente han de someterse a EIA. En un segundo anexo se enumera un conjunto amplio de proyectos a los que, facultativamente, el Estado miembro puede decidir la aplicación de este procedimiento.

La doctrina ha señalado cómo esta técnica de protección medioambiental, a pesar de ser anterior en su formulación legal, se conecta con el IV Programa de Acción Ambiental (1987-1992) por su naturaleza preventiva y por su carácter complementario de otras políticas comunitarias (20).

(18) Vid. A. MANGAS MARTIN, Derecho comunitario europeo y Derecho español. Tecnos, Madrid, 2 edición, 1987, pp. 75 y ss.

(19) Vid. el trabajo de F. FUENTES BODELON, La aplicación de la normativa comunitaria: Balance y perspectivas, en "Revista de Derecho Ambiental", 1988, pp. 10 y ss.

(20) Vid. D. SANCHEZ FERNANDEZ DE GATTA, El cuarto programa de la Comunidad Europea sobre Medio Ambiente. (1987-1992), en "Ordenación del Territorio y Medio Ambiente", Il Congreso Mundial Vasco, HAEE-IVAP, Oñati, 1988, pp. 335. 


\section{B) El Decreto Legislativo 1302/1986, de 28 de junio.}

En cumplimiento de las previsiones europeas, y haciendo uso de la delegación legislativa recepticia, fue aprobado el Real Decreto Legislativo (RDL) 1302/1986, de 22 de junio, desarrollado por Real Decreto (RD) 1131/1988, de 30 de septiembre.

En este conjunto normativo se desarrollan las previsiones ya apuntadas en la Directiva. En coherencia con la Directiva, el RDL condiciona la autorización de los proyectos relacionados en el anexo a la EIA, si bien admite los proyectos excluidos (Defensa Nacional y aprobados por una Ley del Estado) y los exceptuables aprobados por Consejo de Ministros y sometidos a una serie de obligaciones (21).

El proyecto para ser evaluado debe contener un estudio de impacto ambiental que debe incluir una descripción general del mismo; una evaluación de los efectos previsibles directos e indirectos sobre la población, la fauna, la flora, el suelo, el aire, el agua, los factores climáticos, el paisaje y los bienes materiales, incluido el patrimonio histórico-artístico y el arqueológico; las medidas previstas para reducir, eliminar o compensar los efectos ambientales negativos, con posibles alternativas existentes a las condiciones inicialmente previstas en proyecto; un resumen del estudio $y$, finalmente, un programa de vigilancia ambiental (art. 2 del R.D.L. y 7 del R.D.).

Desde el punto de vista que interesa en este momento -el relativo al procedimiento-, dos cuestiones deben ser tratadas. Por un lado, la concerniente al hecho de que la EIA se integra en el procedimiento de autorización, si bien con la necesaria existencia, en caso de ausencia, del trámite de información pública (22). El procedimiento culmina, cuando, con , carácter previo a la resolución administrativa del expediente de autorización o de realización del proyecto, se traslada éste al órgano ambiental competente. El órgano ambiental deberá realizar la declaración de impacto, en la que determine "las condiciones que deban establecerse para la adecuada protección del medio ambiente y de los recursos naturales", de modo que se fije la conveniencia o no de realizar el proyecto o las condiciones, en caso afirmativo, a que deba atenerse.

(21) Vid. ALLI ARANGUREN, Régimen jurídico de la Evaluación de Impacto Ambiental (EIA). Revista Jurídica de Navarra", núm. 8, 1989, pp. 106.

(22) La propia Directiva no prejuzga la necesidad o no de un procedimiento específico. Asi, su art. 2.2 establece lo siguiente:

"La evaluación de las repercusiones sobre el medio ambiente podrá integrarse en los procedimientos existentes de autorización de los proyectos en los Estados miembros, a falta de ellos, en otros procedimientos o en los procedimientos que deberán establecerse para satisfacer los objetivos de la presente Directiva". 
La EIA aparece, según mi punto de vista, como un acto administrativo de trámite que conlleva un informe que, por su propia naturaleza, no podrá ser objeto de convalidación (23). Es más, su conexión con el principio constitucional de protección del medio ambiente reconocido en su art. 45, podría llevar a plantear la nulidad de pleno derecho de una autorización otorgada sin la realización de dicha Declaración, al existir una infracción absoluta del procedimiento. (24) No obstante, como dice CRUZ ALLI, la tendencia jurisprudencial actual que recoge, escrupulosamente, el principio del "favor acti" difícilmente reconocería consecuencias tan radicales. Por lo demás, la posibilidades de paralizar una obra o proyecto que no cuente con EIA paliaría la consideración de su inexistencia como vicio de mera anulabilidad $y$, por lo tanto, sometido a los perentorios plazos de recurso.

Lo que sí parece claro es la posible interposición de recurso a pesar de su naturaleza de acto de trámite, pues se subsumiría dentro de las excepciones a la inimpugnabilidad de este tipo de actos no resolutorios recogidos en el art. 114 de la Ley de Procedimiento Administrativo (25).

En caso de discrepancia entre el órgano ambiental competente y el órgano administrativo que realiza la obra o autoriza el proyecto decidirá el Consejo de Ministros.

(23) Vid. art. 53.3 de la Ley de Procedimiento Administrativo.

En este sentido, J.C. ALLI ARANGUREN, Régimen jurídico ..., cit. pp. 116, tras reconocer la aplicabilidad de este precepto sostiene que más que ante un informe estamos ante "una propuesta ya convertida en acto, preceptiva y vinculante ..."

(24) Reconocimiento de una cierta eficacia juridica de los principios económicos sociales - y muy particularmente del relativo al derecho-deber al medio ambiente- se. viene realizando por la jurisprudencia ya citada del Tribunal Supremo. El más reciente exponente jurisprudencial localizado -dentro de la existencia ya de una jurisprudencia importante de la que es ponente el Pfr. GONZALEZ NAVARRO- lo constituye la Sentencia de 7 de noviembre de 1990 (Azdi. 8750). En este supuesto, un caso de oposición entre el derecho a ejercer una actividad empresarial y la protección del medio ambiente, el Alto Tribunal tuvo oportunidad de manifestar lo siguiente:

"En este problema del respeto por el medio ambiente -en cualquiera de sus manifestaciones, la acústica entre ellas- los Ayuntamientos y, en general, todos los poderes públicos - por tanto, también los Tribunales- tienen que mostrarse particularmente rigurosos. Y este Tribunal Supremo, con machacona insistencia, asi lo viene recordando con apoyo precisamente en el artículo 45 de la Constitución. $Y$ obviamente, esto no es una moda jurisprudencial más o menos pasajera, porque ante preceptos constitucionales tan claros como el citado, no hay opción distinta de la aqui postulada".

(25) Ello resulta evidente en la medida en que la declaración de impacto sea negativa, pues conlleva la denegación de la autorización o no realización del proyecto. También, creo aplicable la impugnación de una declaración positiva, en la medida en que ésta es pública a diferencia de la autorización posterior a la misma. El propio CRUZ ALLI, Régimen jurídico..., cit., pp. 115, considera viable la impugnación tanto de la declaración de impacto como de la propia autorización. 
Un segundo elemento a tener en cuenta lo constituye, precisamente, el órgano ambiental competente. El art. 5 del R.D.L. aporta la siguiente definición:

"A los efectos del presente Real Decreto Legislativo se considera órgano ambiental el que ejerza estas funciones en la Administración Pública donde resida la competencia sustantiva para la realización o autorización del proyecto".

De este modo, la competencia del órgano ambiental autonómico quedará limitada a los proyectos que deban ser realizados por esa misma Administración o aprobados por ella (26).

Mención aparte, en este análisis de la legislación estatal, merecen las potestades de vigilancia y de cumplimiento de la responsabilidades en que se incurran. La regulación encarga a los órganos competentes por razón de la materia estas tareas, si bien se habilita al órgano ambiental para la toma de información y para la verificación del cumplimiento de las obligaciones legales.

Entre las potestades de supervisión y de reacción ante el incumplimiento legal destaca la posibilidad de suspender el proyecto, cuando éste comenzara a ejecutarse sin la EIA o en aquellos casos de ocultación de datos, falseamiento o manipulación maliciosa en el procedimiento de evaluación o cuando concurra, finalmente, el incumplimiento o transgresión de las condiciones ambientales. Esta suspensión se producirá por requerimiento del órgano administrativo del medio ambiente, que deberá efectuar al órgano competente por razón de la materia (27).

(26) El art. 6 del R.D.L. establece que cuando el proyecto tenga repercusiones sobre el medio ambiente de otro Estado miembro de las Comunidades Europeas, el Gobierno pondrá en su conocimiento tanto el contenido del estudio a que se refiere el artículo 2 como el de la declaración de impacto.

El párrafo segundo del precepto mencionado, atribuye, en estos supuestos, la consideración de órgano ambiental al correspondiente de la Administración del Esta. do. Ello en coherencia con la competencia estatal sobre las relaciones internacionales, competencia que el TC ha venido a reconocer de modo, quizá, demasiado amplio, como ha puesto de manifiesto L.A. POMED SANCHEZ en su estudio La proyección exterior de las Comunidades Autónomas ante el Tribunal Constitucional. "RAP", núm. 123, (1991), pp. 211.

(27) CRUZ ALLI (Régimen jurídico...,cit. pp. 110) entiende la existencia de una acción pública para iniciar el proceso de suspensión derivado del art. 28.3 del R.D. $1131 / 1988$, de 30 de septiembre, en la que se prevé que el requerimiento del órgano administrativo del medio ambiente se realice de oficio o a instancia de parte. No me parece afortunada la expresión de acción pública, pues el precepto se limita a establecer la posible denuncia como mecanismo de iniciación de un expediente administrativo. 
Igualmente, el órgano competente por razón de la materia, puede pedir la restitución e indemnización sustitoria cuando se produjera, en expresión del Reglamento, "una alteración de la realidad física o biológica". En este sentido, la Administración puede imponer multas coercitivas de 50.000 pts., sin perjuicio de la ejecución subsidiaria. En cualquier caso, el titular del proyecto deberá proceder a la efectividad de la restitución, cuya valoración será realizada por el órgano ambiental, "previa tasación contradictoria, con intervención del órgano que tenga la competencia sustantiva, cuando el titular del proyecto no prestara su conformidad a aquélla".

\section{LA NORMATIVA ARAGONESA Y EL INSTITUTO ARAGONÉS DEL MEDIO AMBIENTE.}

\section{A) La primera regulación}

La normativa aragonesa encuentra su principio en el Decreto $192 / 1988$, de 20 de diciembre, por el que se distribuyen competencias en materia de evaluación de impacto ambiental (BOA 28 diciembre 1988). En el mismo, se confieren competencias al Consejo de Gobierno en orden a la resolución de discrepancias entre órgano ambiental y órgano con competencia sustantiva y en relación a la exigencia de daños y perjuicios cuando la cuantía de los mismos supere los $50 \mathrm{mi}$ llones de pesetas.

Por su parte, al Consejero del Departamento de Ordenación del Territorio, Obras Públicas y Transportes corresponde el ejercicio de las competencias que la legislación atribuye al órgano ambiental. Sin embargo se produce, en las siguientes funciones encomendadas, una desviación de la regulación estatal, pues se atribuye al titular de este Departamento el conjunto de potestades de suspensión de proyectos, exigencia de responsabilidad de daños y perjuicios y de restitución de la realidad física y biológica, así como el ejercicio de la potestad sancionadora. Aparece, pues, una concentración de funciones en el órgano ambiental más enérgica, incluso, que en la propia regulación estatal.

A este Decreto, le siguió un segundo Reglamento de 19 de septiembre de 1989, (D. 118/1989; BOA de 2 de octubre de 1989), sobre procedimiento de evaluación de impacto ambiental. En él se aborda el contenido del estudio del impacto así como algunas cuestiones procedimentales. Sobresalen, por su importancia, las relacionadas con el trámite de información pública y la precedencia de la declaración de 
impacto con otras autorizaciones (28). En este sentido, el art. 5 expresa lo siguiente:

“El procedimiento de impacto, que terminará con la declaración de impacto por el Consejero de Ordenación del Territorio, Obras Públicas y Transportes o con la resolución de discrepancias entre aquél y el órgano autorizante o decisor por el Consejo de Gobierno de la Diputación General de Aragón, deberá proceder a las autorizaciones y acuerdos decisorios que sobre proyectos públicos o privados de obras, instalaciones o actividades sometidos a evaluación de impacto, correspondan a los distintos órganos de la Administración autonómica".

Precedencia que, en el artículo siguiente, se extiende a la intervención de las Comisiones Provinciales de Urbanismo, en materia urbanística, así como a la de las comisiones Provinciales de Medio Ambiente por aplicación del Reglamento de Actividades Molestas, Nocivas, Insalubres y Peligrosas.

Por su parte, el Decreto también contiene normas competenciales al conferir a los órganos competentes el seguimiento y vigilancia del cumplimiento del contenido de la declaración de impacto ambiental, del que darán cuenta al Consejo de Ordenación Territorial, Obras Públicas y Transportes, que conserva sus cometidos del anterior Decreto y se le adiciona plena capacidad de denuncia en la materia.

\section{B) La creación del Instituto Aragonés del Medio Ambiente y el D. 148/1990.}

El Instituto Aragonés del Medio Ambiente -creado por $D$. 128/1989, de 17 de octubre- se configura como un servicio administrativo dependiente de la Presidencia del Gobierno. Está compuesto por un Consejo de Dirección, por una Dirección de Gerencia y por una Secretaría General (29). Su nacimiento se produce en un clima

(28) En coherencia con lo establecido en la Disposición adicional, letra d) del R.D. $1131 / 1988$.

(29) El fin coordinador de este órgano queda patente en los miembros que integran el Consejo de Dirección. Asi, el art. 4 del D. 128/1989 establece lo siguiente:

"El Consejo de Dirección estará compuesto por el Presidente de la Diputación General con facultades delegables en un Consejero y, además, por los siguientes Vocales:

- Consejero de Presidencia.

- Consejeros de Ordenación Territorial, de Agricultura, de Industria y de Sanidad.

- Presidente del Consejo Asesor de Investigación.

- Director Gerente del Instituto Aragonés del Medio Ambiente.

- Tres personas designadas por el Consejo de Gobierno entre aquéllas de reconocido prestigio en especialidades relacionadas con el desarrollo y medio ambiente ..." 
de cierta superposición organizativa, pues existia todo un aparato organizativo:

a) Organos consultivos, como la Comisión del Medio Ambiente de Aragón que evacuaba informes en determinados asuntos.

b) Organos de coordinación, como la Comisión Interdepartamental de Ordenación del Territorio y Medio Ambiente.

c) Comisiones Provinciales de Medio Ambiente, con funciones relativas al Reglamento de Actividades Molestas, Insalubres, Nocivas y Peligrosas.

A pesar de la existencia de cierta complicación y de la competencia de diferentes Departamentos (30), es necesario reconocer que se había operado una cierta concentración de funciones ambientales en el Departamento de Ordenación Territorial, Obras Públicas y Transportes, que afectaba a EIA y a las atribuciones en materia de residuos tóxicos y peligrosos. Era, por cierto, un proceso paralelo al ocurrido en las mismas materias en la Administración del Estado donde el Ministerio de Obras Públicas y Urbanismo -concretamente en su Secretaría General del Medio Ambiente- había aglutinado las competencias en las cuestiones citadas (31).

Es en este contexto, cuando surge el Instituto Aragonés del Medio Ambiente con diferentes funciones de fomento de investigación $y$ de asesoría pero, sobre todo, caracterizado por la emanación de informes en materia de EIA.

(30) Vid. J. DOMPER quien estructura su trabajo Las facultades de intervención de la Comunidad Autónoma en el medio ambiente, y su regulación específica, en "Derecho Público Aragonés", Zaragoza, 1990, pp. 563 y ss.) en función de las competencias de los cuatro Departamentos competentes.

(31) No obstante, como afirma L. ORTEGA (Organización del medio ambiente: la propuesta de una autoridad nacional para el medio ambiente, en "Estudios sobre la Constitución Española. Homenaje al Profesor Eduardo Garcia de Enterria" IV, ed. Civitas, Madrid, 1991, pp. 3784) se estaba lejos -y se está más todavía con el reforzamiento del antiguo MOPU en la reciente reorganización ministerial- de un órgano sobre el que recayesen las competencias medioambientales existentes en los diferentes Departamentos ministeriales. Lamentablemente, la propuesta del Pfr. ORTEGA ALVAREZ de creación de un Ministerio del Medio Ambiente o de una Secretaria de Estado con las mismas funciones, dependiente del Ministerio de Economia, y, por lo tanto, alejada de Ministerios con competencias sectoriales que puedan encontrarse con el respeto medioambiental, no ha tenido éxito en el nuevo ajuste ministerial.

Vid., con iguales planteamientos de centralización administrativa, V. RODRIGUEZ VAZQUEZ DE PRADA, Medio ambiente: Análisis comparativo de la normativa comunitaria y española, con especial referencia a la actuación de las Corporaciones Locales. "REVL/REALA", núm. 248, (1990), pp. 776. 
Sin embargo, lo que podría haber sido el embrión de un organismo autónomo con funciones ambientales no se ha visto correspondido por la regulación aprobada poco después. Efectivamente, el D. 148/1990, de 9 de noviembre, de la Diputación General de Aragón, por el que se regula el procedimiento para la declaración de impacto ambiental ha supuesto una dispersión organizativa (32).

Tres son los principios que informan este Decreto, según su Exposición de Motivos:

a) Que la EIA sea contrastada previamente por un órgano técnico especializado en materias de medio ambiente, como es el Instituto Aragonés del Medio Ambiente.

b) Que sea aplicado el principio de participación con la amplitud deseable y con la formulación, en su caso, de consultas a personas públicas o privadas potencialmente afectadas.

c) Que el Consejo de Gobierno pueda someter a EIA los proyectos en los que puedan concurrir "circunstancias de relevancia palmaria", a pesar de no estar incluidos en el anexo del RDL.

Nuevamente, se incluyen en el Decreto cuestiones procedimentales siendo reguladas con gran exhaustividad, en ocasiones excesiva. Asi, por ejemplo, se establece que el proyecto deba ser presentado en el Registro de la Diputación General de Aragón. Parece evidente que el promotor del proyecto, con independencia de lo estipulado en este precepto, pueda hacer uso de la presentación de escritos en las Oficinas de Correos por procedimiento administrativo del art. 66 de la LPA, toda vez que esta posibilidad se incluye dentro del procedimiento administrativo común (33).

Pero, sin duda, lo más llamativo es que la Declaración de Impacto Ambiental será realizada por el titular del Departamento al que corresponda la competencia material, de manera, que según el art. 10.2, "se considera órgano ambiental al propio Departamento en el que resida la atribución sustantiva para la realización o autorización del proyecto al que la declaración de impacto ambiental se refiera". Antes de que se produzca este acuerdo del Consejo correspondiente, es preceptivo el informe del IAMA, concretamente de su Dirección de Gerencia.

(32) La corrección de errores del citado D. aparece en el BOA de 6 de marzo de 1991.

(33) Vid., en este sentido, J. GONZALEZ PEREZ, Comentarios a la Ley de Procedimiento Administrativo. de. Civitas, Madrid, 1988, pp. 500. 
En caso de discrepancia entre el IAMA y el órgano ambiental, que -insisto- coincide con el órgano de competencia material, corresponde la declaración al Consejo de Gobierno.

Esta proliferación de órganos ambientales va en contra de toda racionalidad administrativa, ya no sólo por hacer coincidir en el mismo órgano la competencia sustantiva y la declaración de impacto ambiental, sino, también, por oponerse a la necesaria concentración organizativa de órganos ambientales en la CA. Por lo demás, se llega al absurdo de que las competencias -descritas en la legislación estataldel órgano ambiental de recabar informes y supervisar la observancia por los autoridades con competencia material carecen de sentido, debido a que el IAMA se ve privado de estas funciones que quedan aglutinadas en cada uno de los Departamentos.

Una segunda cuestión plantea una serie de problemas, y es la relativa a la posibilidad de que el Consejo de Gobierno estime la conveniencia de someter a EIA determinada obra o proyecto. Sirva lo dicho en lo concerniente a la distribución competencial para justificar la competencia autonómica para regular esta medida, pues se incardinaría desde mi punto de vista, dentro de las materias vinculadas al medio ambiente o directamente relacionadas con él como los espacios naturales protegidos (34). En este sentido, me parece que hubiese sido plausible añadir alguna innovación a las obras y actividades sujetas a EIA (siguiendo el ejemplo de la Ley valenciana 2/1989, de 3 de marzo, de Impacto Ambiental (35) y no limitarse a la reproducción del anexo del RDL.

Finalmente, el propio Decreto es consciente de las dificultades de interpretación entre las diferentes normas citadas -a las que añade,

(34) Por su conexión con atribuciones autonómicas relacionadas con el medio ambiente como las zonas de montaña, la agricultura, el urbanismo y la ordenación del territorio, los montes, los aprovechamientos forestales o los propios espacios naturales protegidos, considero que, dentro de los limites de estos conceptos, podria añadirse a la lista estatal de proyectos sometidos a EIA, aquellos otros supuestos que se estimase conveniente incluir. Piénsese, en este sentido, la bondad de fiscalizar con esta técnica numerosos proyectos públicos y privados que convendria evaluar en las zonas de montaña de nuestra CA y, particularmente, en el Pirineo.

No obstante, creo que múltiples actuaciones en estas zonas de montaña, especialmente las vinculadas a determinados proyectos olimpicos, podrian subsumirse en la ampliación en un supuesto del anexo de D.L. por la Ley de Espacios Naturales Protegidos y de Protección de la Flora y Fauna Silvestre, recogida en su disposición adicional segunda ("transformaciones de uso del suelo que impliquen eliminación de la cubierta vegetal, arbustiva o arbórea y supongan riesgo potencial para las infraestructuras de interés general de la Nación y, en todo caso, cuando dichas transformaciones afecten a superficies superiores a 100 hectáreas").

(35) Vid. el anexo de la norma valenciana (BOE de 12 de abril). En igual sentido, puede consultarse el Anexo II de la reciente Ley madrileña 10/1991, de 4 de abril, para la Protección del Medio Ambiente. 
entre otras disposiciones, las correspondientes a residuos tóxicos y peligrosos (36). La Disposición Adicional Primera tiene el siguiente tenor:

"Se faculta al Departamento de Presidencia y Relaciones Institucionales para que proponga a la aprobación del Consejo de Gobierno un texto refundidor de los Decretos 191/1988, de 20 de diciembre, 192/1988, de 20 de diciembre, 139/1988, de 16 de agosto, 128/1989, de 17 de octubre, y de cualesquiera disposiciones de igual rango afectadas por las previsiones de este Decreto".

Ese futuro Decreto debería vincularse a una reforma organizativa en la materia que tendiera a una centralización de competencias en un órgano administrativo, con propia personalidad juridica (37), que tuviera las competencias medioambientales o con la creación de un Departamento ad hoc en medio ambiente y ordenación del territorio (38). Esta última opción que parece la más plausible sería absolutamente necesaria si se produjera la prevista reforma estatutaria.

(36) A pesar de que la Disposición no se refiere al Dto. 85/1990, de 5 de junio, de medidas urgentes de protección urbanistica en Aragón, entiendo la conveniencia de tener en cuenta al mismo en la futura redacción de un Decreto de refundición. BOQUERA OLIVER Suelo y Vivienda "Derecho Público Aragonés", Zaragoza, 1990, pp. 547) realiza una exégesis a esta norma, según la cual las Comisiones Provinciales de Urbanismo -en una serie de zonas de especial protección- deberán autorizar la concesión de licencias, autorizaciones o concesiones. El Profesor BOQUERA entiende, a su vez, que las Comisiones tienen la facultad de exigir la incorporación al expediente de solicitud de la licencia un estudio de Evaluación de Impacto Ambiental.

(37) Asi lo estima. J. DOMPER FERRANDO, Las facultades de intervención ...,cit. pp. 604-605.

(38) Recientemente ha sido creado por Ley 4/1991, de 22 de marzo, un Departamento de Medio Ambiente en la Generalitat catalana, desgajado, por cierto, del de Politica Territorial y Obras Públicas. Sin embargo, en la Comunidad Foral Navarra existe una Consejería de Medio Ambiente y Ordenación del Territorio. La unión de ambas funciones administrativas en un mismo Departamento dependerá, según mi punto de vista, del sentido y alcance que se dé al concepto de ordenación del territorio. En este sentido, si por tal entendemos una ordenación, entre otras cosa, de inversiones públicas parece razonable su separación de la autoridad del medio ambiente. Sin embargo, si se parte de una ordenación del territorio como directora de la planificación urbanistica municipal es coherente su agrupación con la organización del medio ambiente. 
